\section{Z. Slim and S. Bernatsky reply}

To the Editor:

Indeed, self-report is not a perfect method to ascertain rheumatoid arthritis (RA) cases. RA is not a well-defined disease from the perspective of a lay person; therefore, underreporting and/or overreporting are very possible in health surveys ${ }^{1}$. The objective of our study was to highlight the issue of misclassification error, which is inherent in both self-report and health administrative data. Given the problems with estimating RA prevalence using a single source of information (including self-report), we provide an analytical approach to obtain unbiased prevalence estimates, using multiple data sources. Indeed, our results are consistent with the premise that the unadjusted prevalence estimate of self-reported RA in CARTaGENE is an overestimate $[2.9 \%$; $95 \%$ credible interval (CrI) 2.6-3.1] compared to the adjusted one $(1.3 \% ; 95 \% \mathrm{CrI} 0.07-3.2)^{2}$, which were both reported in our article.

In the literature, a wide range of RA prevalence estimates are evident, between $0.4 \%$ and $8 \%$ worldwide ${ }^{3,4}$. Such estimates rarely adjust for misclassification error. Some have attempted to validate self-reported questionnaire data against medical charts ${ }^{5}$. However, previous research has shown that using medical charts to validate population-based data may overlook some chronic disease cases, particularly if one care provider is the single source of charted information ${ }^{6}$. Further, using a reference standard such as clinical verification by a doctor or using RA classification criteria across many participants in large prevalence studies is cumbersome and rarely practical. Therefore, self-report surveys and health administrative databases represent cost-effective and feasible sources of data for RA prevalence estimates, even though they are not perfect.

Comparing our results to other recent Canadian studies, we note that in our study, the 3-year 2010 RA point prevalence estimate among adults aged 40-69 years, combining self-report data with administrative billing code information, was $0.9 \%$ (95\% CrI 0.7-1.2). This estimate exactly matches the RA prevalence estimate ( $0.9 \%$ ) from a study using Ontario administrative health data (without adjustment for imperfect case definitions) ${ }^{7}$ although it is somewhat higher than the adjusted RA estimate $(0.48 \%)$ that we generated in Quebec in 2008 using only health administrative data ${ }^{8}$. In the 2005 Canadian Community Health Survey, self-reported RA prevalence was about $3.8 \%{ }^{9}$, which is very similar to our self-report data.

To address the issues of false positives and false negatives in any single data source, we continue to recommend the use of multiple data sources (where possible), and to adjust for the inherent misclassification error in each data source.
ZEINAB SLIM, PhD, Department of Epidemiology, Biostatistics and Occupational Health, McGill University, and Division of Clinical Epidemiology, Research Institute of the McGill University Health Centre; SASHA BERNATSKY ${ }^{\circ}$, MD, PhD, Professor of Medicine, Department of Epidemiology, Biostatistics and Occupational Health, McGill University, and Division of Clinical Epidemiology, Research Institute of the McGill University Health Centre, Montreal, Quebec, Canada. Address correspondence to Dr. S. Bernatsky, Research Institute of the McGill University Health Centre, 5252 boul. de Maisonneuve Ouest, 3F.51 Montreal, Quebec H4A 3S5, Canada. E-mail: Sasha.bernatsky@mcgill.ca

\section{REFERENCES}

1. Singh JA. Discordance between self-report of physician diagnosis and administrative database diagnosis of arthritis and its predictors. J Rheumatol 2009;36:2000-8.

2. Slim Z. Estimating rheumatoid arthritis prevalence and care quality in a large sample from the Quebec population [doctoral dissertation]. Montreal: McGill University; 2018.

3. Kvien TK. Epidemiology and burden of illness of rheumatoid arthritis. Pharmacoeconomics 2004;22:1-12.

4. Uhlig T, Moe RH, Kvien TK. The burden of disease in rheumatoid arthritis. Pharmacoeconomics 2014;32:841-51.

5. Kvien T, Glennås A, Knudsrød O, Smedstad L. The validity of self-reported diagnosis of rheumatoid arthritis: results from a population survey followed by clinical examinations. J Rheumatol 1996;23:1866-71.

6. Hux JE, Ivis F, Flintoft V, Bica A. Diabetes in Ontario. Diabetes Care 2002;25:512.

7. Widdifield J, Paterson JM, Bernatsky S, Tu K, Tomlinson G, Kuriya $\mathrm{B}$, et al. The epidemiology of rheumatoid arthritis in Ontario, Canada. Arthritis Rheumatol 2014;66:786-93.

8. Bernatsky S, Dekis A, Hudson M, Pineau CA, Boire G, Fortin PR, et al. Rheumatoid arthritis prevalence in Quebec. BMC Res Notes 2014;7:937.

9. Gariepy G, Rossignol M, Lippman A. Characteristics of subjects self-reporting arthritis in a population health survey: distinguishing between types of arthritis. Can J Public Health 2009;100:467-71.

First Release February 15 2020; J Rheumatol 2020;47:5; doi: $10.3899 /$ jrheum. 200026 